\title{
CHRONIC NEPHRITIS WITH AND WITHOUT EDEMA: A STUDY OF CHOLESTEROL IN THESE CONDITIONS
}

\author{
BY FRANCIS D. MURPHY
}

(From the Medical Clinic of Milwaukee County Hospital)

(Received for publication August 5, 1927)

Many attempts have been made to correlate the clinical symptoms and pathological changes in the kidney of chronic nephritis, but so far, no general agreement prevails concerning the importance of numerous factors held partially accountable for some of the chief symptoms. This is well illustrated in the case of edema, where many theories have been advanced to explain its presence, and have not been generally accepted, as shown by the extensive review of Loeb (1).

Recently, considerable attention has been given to changes in the protein and lipoid content of the blood plasma in renal diseases especially in cases of pure lipoid nephrosis. Numerous studies have appeared dealing with protein changes and their relation to symptoms of nephritis, while comparatively few have dealt with cholesterol and its association with nephritis. This article takes up observations made on a series of cases of chronic nephritis with and without edema and includes a few cases of hypertensive cardiovascular disease with edema from heart failure. The changes in the blood cholesterol, the presence of cholesterol esters in the urine and in the tubular epithelium in those conditions are especially dealt with. To avoid confusion, it should be understood that no cases of pure lipoid nephrosis are included here. The latter condition was studied and reported upon elsewhere (2).

Of the thirty-one cases reported here, twenty-five had chronic nephritis and six were cases of hypertensive cardiovascular disease with edema from heart failure. Of the twenty-five patients with chronic nephritis, fourteen were edematous; in eleven no edema appeared; seventeen died, and fourteen of these were examined post mortem. Three of the six patients with hypertensive cardiovascular disease died and were examined post mortem. 
All of the patients classed as nephritis showed extensive glomerular involvement and the tubules were diseased in varying degree, from cloudy swelling to complete obliteration. Clinically, all the cases of nephritis under consideration fulfilled the requirements for a diagnosis of chronic diffuse glomerular nephritis. Under older classifications, those cases showing the edema, a heavy albuminuria, with slight retention of nitrogenous products would be classed as chronic parenchymatous, while those with no edema, an excessive retention of nitrogenous products in the blood, and a great elevation of the blood pressure, would be placed with the chronic interstitial type. Under the classification of Christian (3) many of these cases would correspond to his combined type; chronic nephritis with edema and hypertension; the others would conform to his group: chronic nephritis with hypertension. Large and small white kidneys, mottled kidneys, and granular kidneys were found in this series. It seems significant that the edema appeared to be independent of either glomerular involvement or of simple tubular degeneration. The size, shape or color of the kidney bore no relation to the dropsy. Histologically, all cases exhibited tubular changes but those of the group showing edema were characterized by a special type of disease, namely, a lipoid deposit in the tubular epithelium, while those having no edema, had no lipoid deposit in the tubular epithelium.

The chief object of this paper is to show that there exists an association between chronic glomerular nephritis with edema on the one hand, and on the other, the following group of conditions: an elevation of the blood cholesterol, deposits of lipoid material in the tubular epithelium and the presence of doubly refracting lipoid bodies in the urine. As to the character of the association of the edema and the conditions mentioned-whether it points to a relationship as of cause and effect-even in the face of grave suspicion arising from a study of the cases, prudence suggests that judgment be suspended. For while these findings are present too constantly to be considered as mere coincidence, the significance of them in connection with the presence or absence of edema is obscure and may be related to other factors whose importance in this connection is still unknown. 
COMMENT ON CASE HISTORIES AND AUTOPSY FINDINGS

(For detailed data see tables 1, 2 and 3, and appended protocols.) The cases presented may be divided into three groups: Group I, patients with chronic nephritis with edema (table 1); Group II, patients with chronic nephritis with no edema (table 2); and Group III, patients with hypertensive cardiovascular disease with edema from heart failure (table 3). Besides the routine examinations, the blood cholesterol was determined and the urine examined for doubly refracting lipoids in each case, and where autopsies were performed the tissue was examined for doubly refracting lipoids.

\section{Cases in Group I (table 1)}

There were fourteen cases in this group; nine of them died of uremia and five are living. A post mortem examination was made in six. The chief clinical findings were edema, hypertension, hematuria and a reduced renal function progressing to a serious degree of renal insufficiency and terminating in uremia. Usually there was an elevation of blood cholesterol, although in case 12 it was subnormal and in case 2 it was only slightly elevated. The edema was usually not persistent, but came and went at irregular intervals and was not influenced to a great extent by any treatment instituted. Hypertension of varying degrees was present in all cases. There was some elevation of blood urea nitrogen in all cases, although in case 10, the increase was not great. Doubly refracting lipoids were found almost constantly in the urinary sediment of all cases except in case 12 where none was found on repeated examination. These lipoids were found regularly in all the cases during edema free period. It can be said that the magnitude of the edema was not matched by the number of doubly refracting lipoids present in the urine. It may also be stated that the degree of hypercholesterolemia did not parallel the amount of edema at all times. There was an extensive edema in case 6 at a time when the blood cholesterol was less than usual. Of the kidneys of this group examined post mortem, all had doubly refracting lipoids in the renal tubular epithelium, including case 12, in which none was found in the urine during ante-mortem observation. The lipoids were found in the convoluted and straight tubules as a rule, and at 


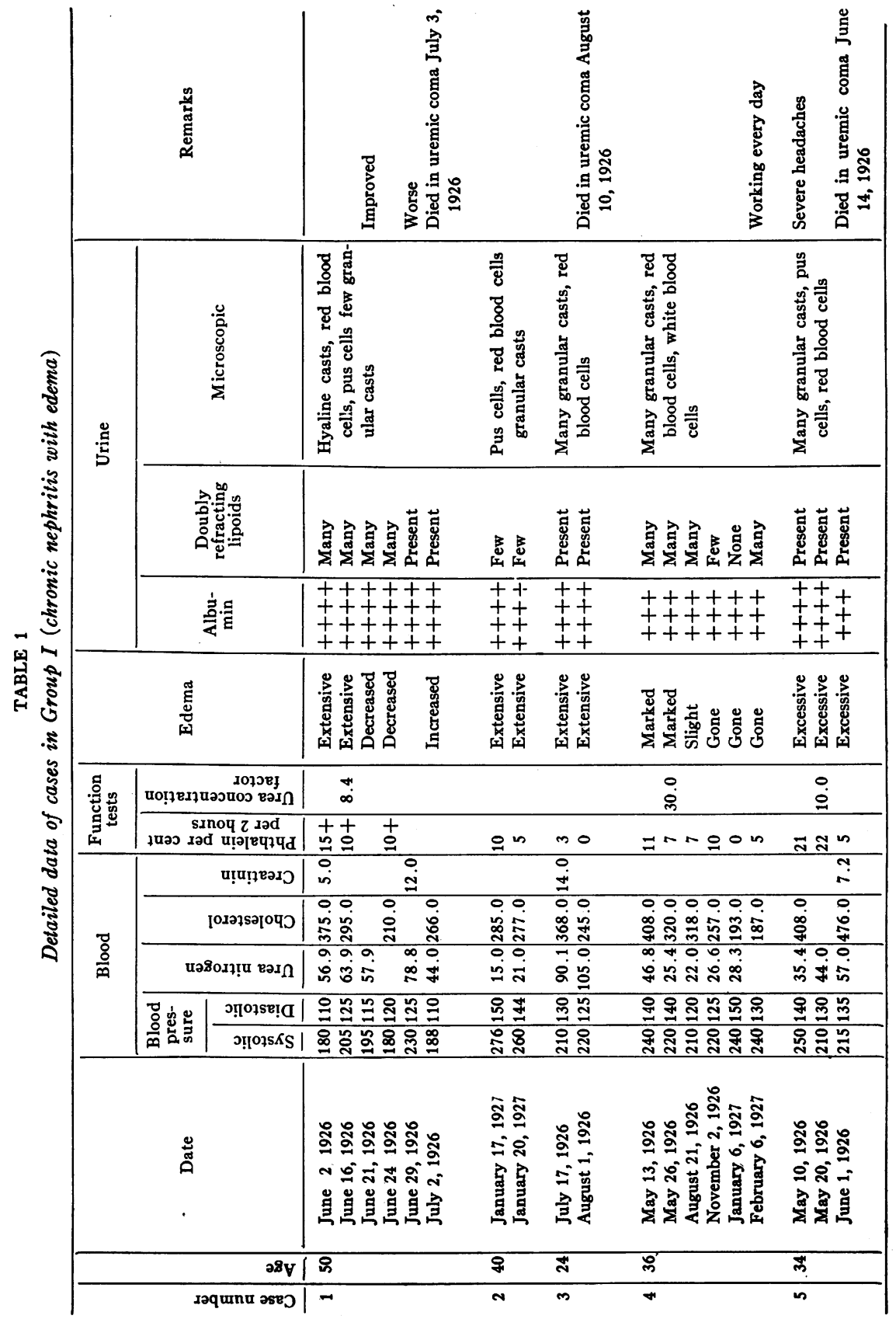




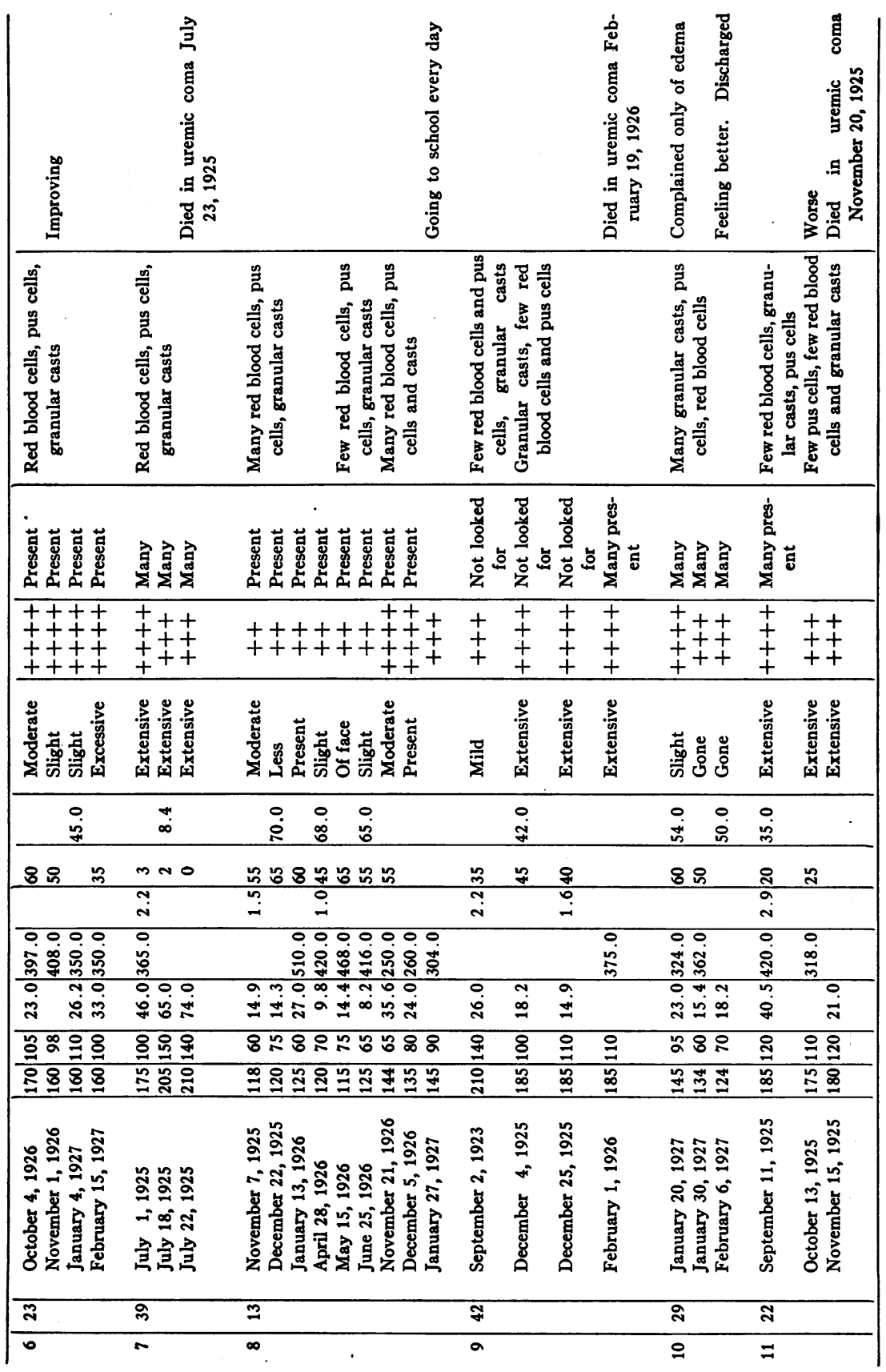

THE JOURNAL OF CLINICAL INVHATIGATION, vOL. $v$, No. 1 


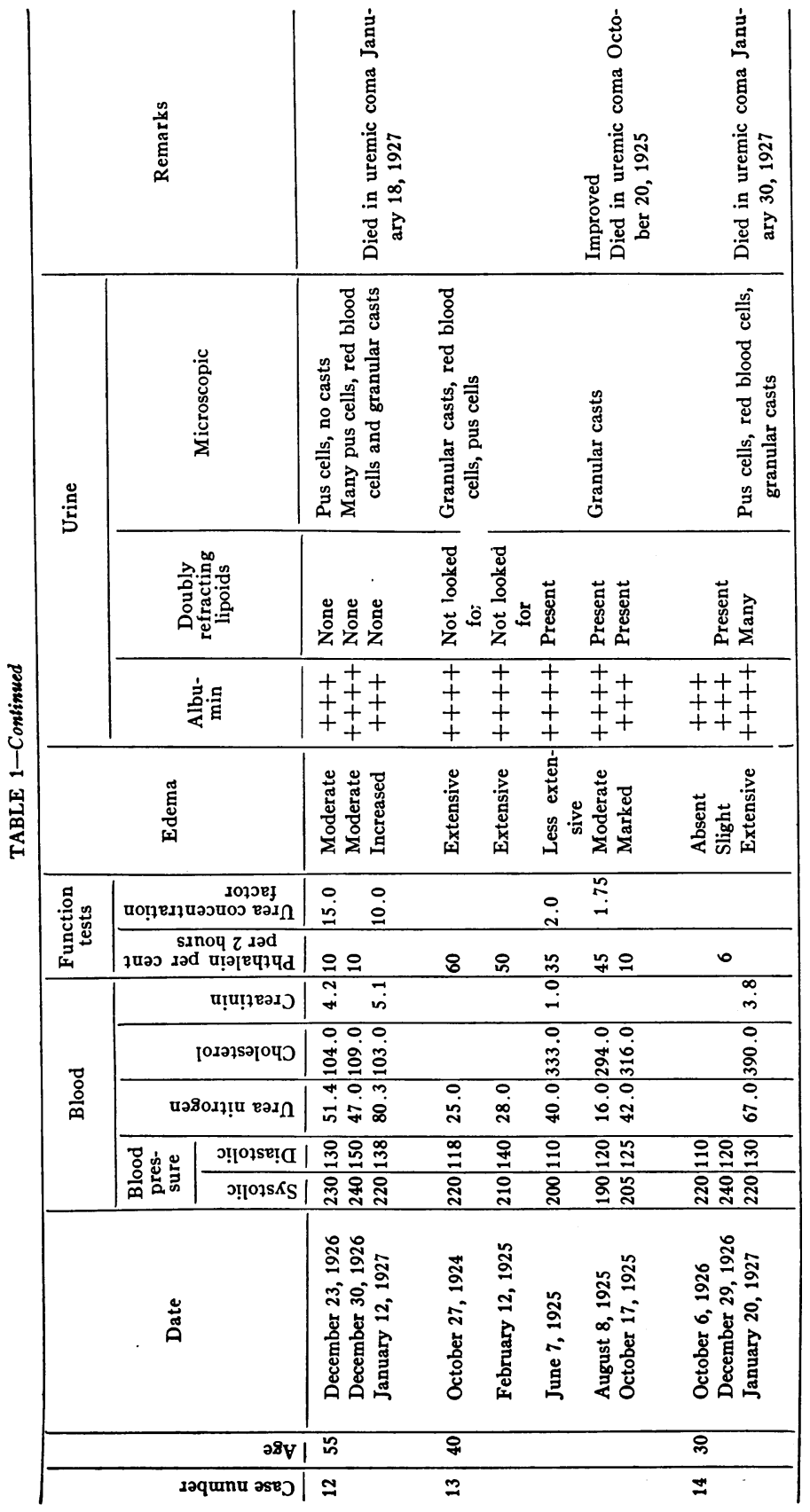


times in the interstitial tissue. Tissues were stained for fat and it should be emphasized that not all the fat was doubly refracting but that there was a mixture of fats present.

At times, cases similar to those in this group are called by some, pure lipoid nephrosis because of the presence of edema, hypercholesterolemia and doubly refracting lipoids. Confusion may arise between pure lipoid nephrosis and chronic glomerular nephritis with secondary lipoid degeneration in conditions as in case 10 . Case 10 showed edema, hypercholesterolemia, doubly refracting lipoids in the urine and albuminuria; findings common to both conditions. The elevation of the blood pressure and the presence of red blood cells and granular casts in the urine served to make a diagnosis of glomerular nephritis. When patients hav- a quiescent chronic glomerular nephritis, with albuminuria and very $\mathrm{fr}_{\mathrm{w}} \mathrm{w}$ cellular elements, the history of having had indications of glomerular nephritis previously may help in the differential diagnosis. The hypercholesterolemia usually is greater in pure lipoid nephrosis than in chronic glomerular nephritis with secondary lipoid degeneration of the tubules. Histological examination of renal tissue from patients with pure lipoid nephrosis shows the glomeruli to be practically normal and that from patients with chronic glomerular nephritis with secondary lipoid degeneration of the tubules reveals well defined glomerular lesions. The distribution of lipoid deposits is quite uniform in the former condition, while in the latter there is a selective arrangement of the deposits. Dewey (4) observed a selective localization of lipoids in the renal tubules in animals injected with cholesterol. In all the cases of Group I (with edema), where post mortem examination of the kidney was made, the tubules showed deposits of doubly refracting lipoids. There was a mixture of cholesterol esters and other fats. The association appears to be closer between edema and deposits of lipoids in the tubules than between the hypercholesterolemia and edema, or the lipoids in the sediment and edema.

\section{Cases in Group II (table 2)}

There were eleven cases in this group, and of them ten died and were examined post mortem. Clinically the cardinal signs and symptoms of chronic glomerular nephritis were present, but in contrast to 


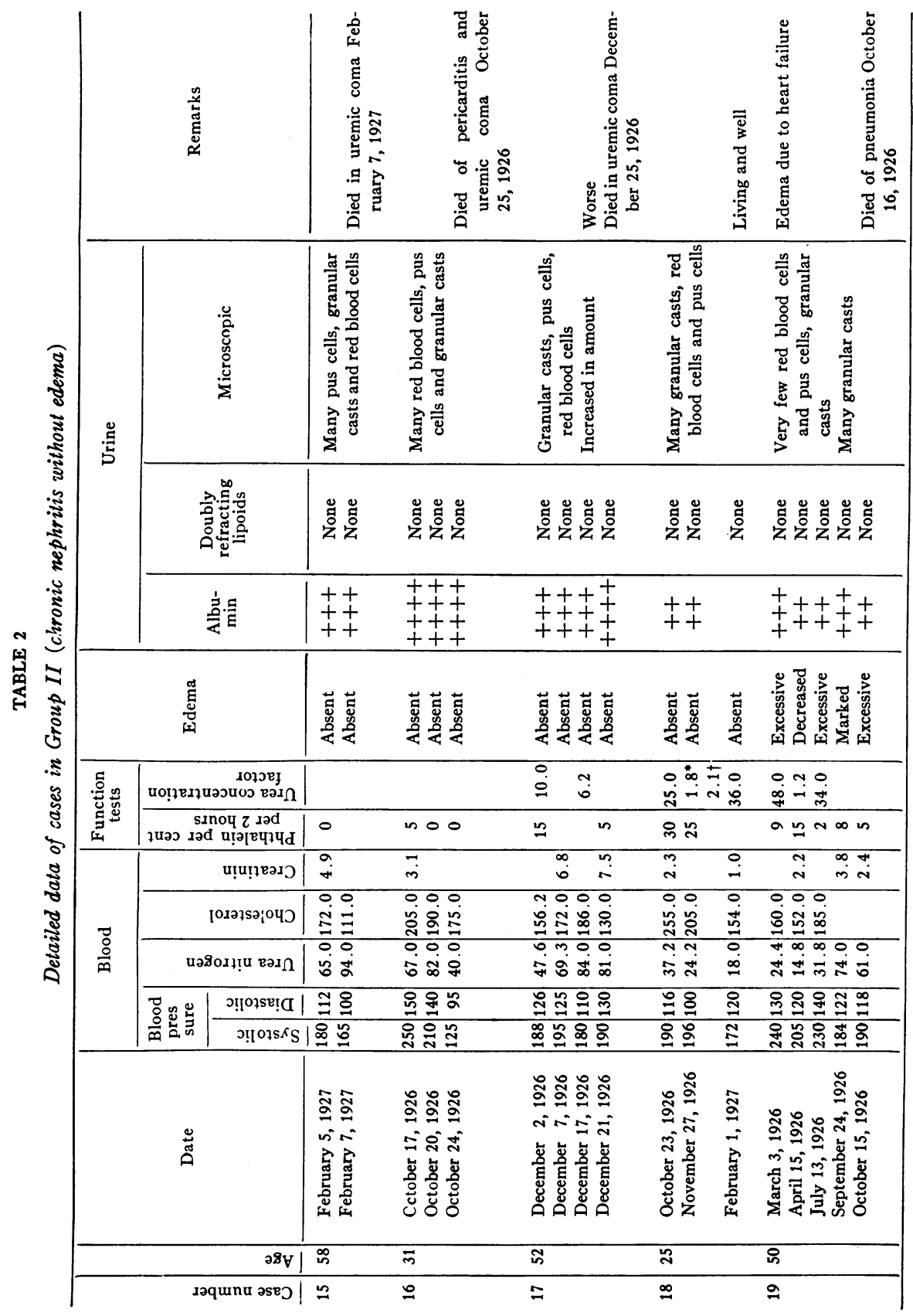




\begin{tabular}{|c|c|c|c|c|c|}
\hline 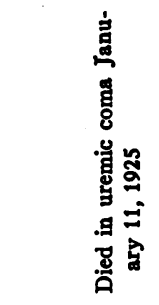 & 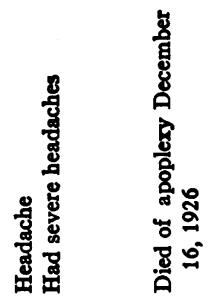 & 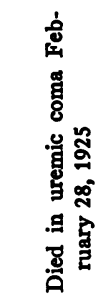 & 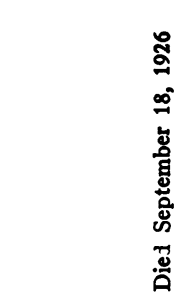 & 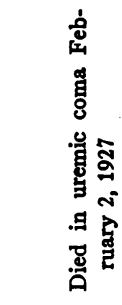 & 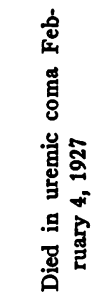 \\
\hline 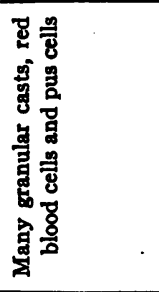 & 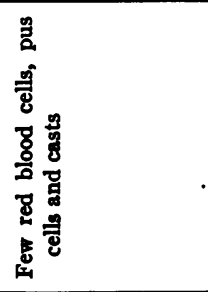 & 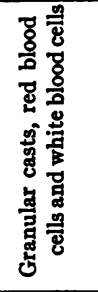 & 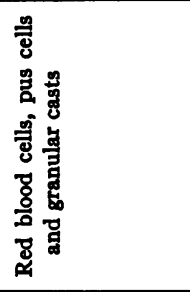 & 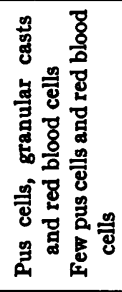 & 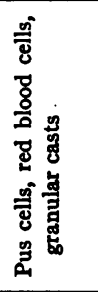 \\
\hline : & 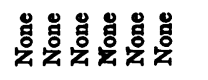 & : & 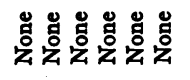 & 莣 苔 & 苋哭 \\
\hline 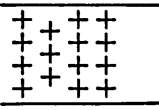 & +++++ & $\begin{array}{l}+t \\
++ \\
+t\end{array}$ & $\begin{array}{l}++++++ \\
+++++ \\
+++++ \\
++\end{array}$ & 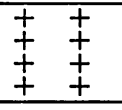 & $\begin{array}{l}+t \\
+ \pm \\
+ \pm \\
++\end{array}$ \\
\hline 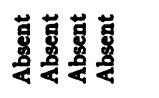 & 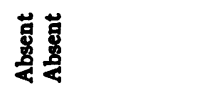 & 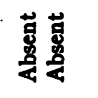 & 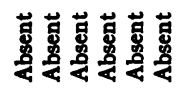 & 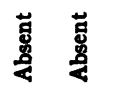 & 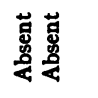 \\
\hline & $\begin{array}{lll}\circ & 0 & 0 \\
\dot{8} & \stackrel{j}{j} & \text { j } \\
\end{array}$ & & $\stackrel{0}{\dot{m}} \quad \stackrel{0}{a}$ & & \\
\hline $\sin \sin 0$ & $\leadsto \approx \quad \leadsto$ & 00 & 웅ㅇㅁ요잉 & & \\
\hline$\ddot{i} \vec{i}$ & & $\stackrel{0}{\circ}$ & $\stackrel{m}{n} \stackrel{+}{=} \stackrel{\infty}{=}$ & $a$ & $\overline{7}$ \\
\hline 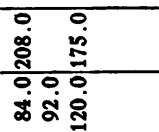 & 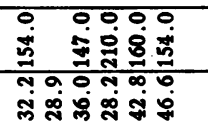 & 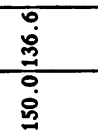 & 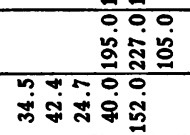 & 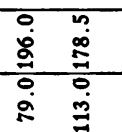 & $\begin{array}{l}0 \\
\dot{0} \\
\dddot{0} \\
0 \\
\dot{0}\end{array}$ \\
\hline 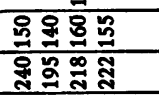 & 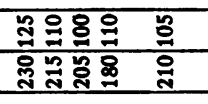 & 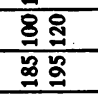 & 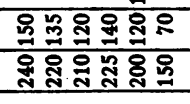 & 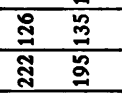 & 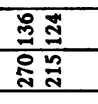 \\
\hline 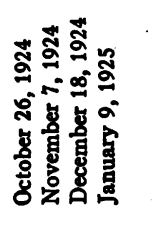 & 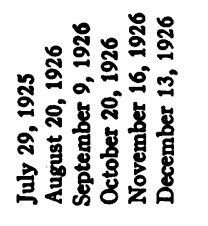 & 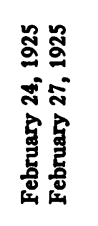 & 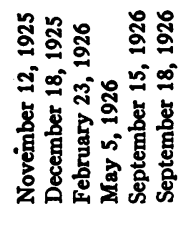 & 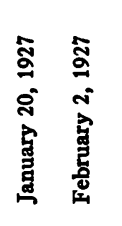 & 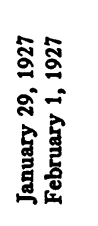 \\
\hline F & $\approx$ & י্ల & స్ల & $F$ & 9 \\
\hline ฉి & $\vec{\pi}$ & జี & $\tilde{\pi}$ & $\approx$ & $\approx$ \\
\hline
\end{tabular}


Group I, edema was absent. The blood cholesterol at times was elevated although usually it was normal or subnormal. No doubly refracting lipoids were found in the urinary sediments. These patients were for the most part older than those of Group I. Uremia terminated the course of the disease in eight cases and a plastic pericarditis was associated with uremia in three of them. In case 19, edema was present that had the features of a cardiac edema; findings also were present pointing to renal disease; the post mortem and clinical data indicated that the kidneys were severely damaged and for that reason the case is included in this group. All other cases in this group were free from edema. Practically all of the patients had unmistakable signs and symptoms of chronic diffuse glomerular nephritis. Cases 17 and 19 were diagnosed malignant hypertension (renal type) because of the extensive involvement of the arterioles and a history that pointed to a long standing hypertension. The lipoid deposits seemed not to be influenced by the fact that the disease began in the arterioles of the kidney or in the glomeruli proper. Histologically, well developed chronic glomerular nephritis was found in all cases examined. The tubular epithelial cells were usually found to be extensively diseased but no doubly refracting lipoids were found in them. In cases 15, 20 and 24, fatty material was found with fat stains in the tubular cells, but none of this fat was doubly refracting.

\section{Cases in Group III (table 3)}

Of the six cases in this group, two died of heart failure and one of pulmonary embolism. The three were examined post mortem. These cases are included to demonstrate that the presence of edema in this type of disease is not associated, as a rule, with doubly refracting lipoids in the urine or in the renal tubules. Clinically, edema, chronic hypertension, and cardiac hypertrophy were the chief features. No doubly refracting lipoids were found in the urine except in case 29 , where a few were found occasionally in the urinary sediment. The blood chemical data and renal function tests revealed less kidney involvement than in the first and second groups. There was no hypercholesterolemia. By comparing the results of polariscopic examination of the urine and renal tissues of this group with Group $\mathrm{I}$, it is seen that here doubly refracting lipoids were practically always 
FRANCIS D. MURPHY

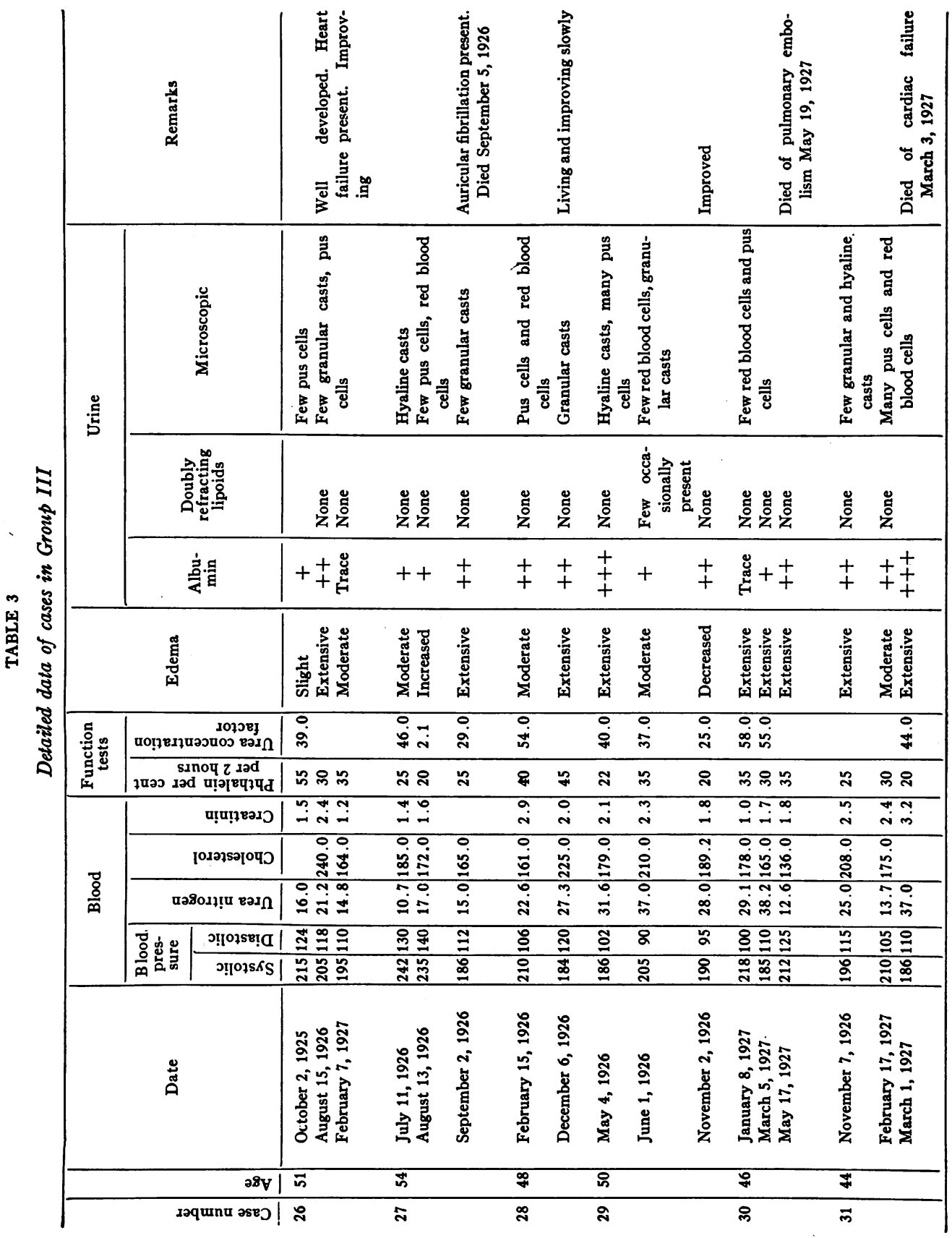


absent (except case 29), while they were constantly present in Group I. At post mortem examination, the chief changes in the kidneys were lesions involving the smallest arterioles and an interstitial fibrosis. The glomeruli were also diseased but not so uniformly nor so extensively as in Groups I and II. Some glomeruli were found hyalinized and there was a moderate amount of capsular fibrosis. Many glomeruli were enlarged and others appeared normal. The tubular epithelial cells were found to be considerably less involved than those in the other groups. The diagnosis of this group depended more upon the clinical history, the renal function tests and the blood chemistry than on the histological examination. Usually these patients gave a history of having had hypertension with little or no albuminuria for years. In case 31 , fatty material was found, but none of it was doubly refracting. None of the other kidneys of the group examined showed fat of any kind in the renal parenchyma.

THE POLARIZING MICROSCOPE

The use of the polarizing microscope in the differentiation of certain fatty substances was introduced in 1858 by a German physician, Mettenheimer (5). He called attention to the anisotropic nature of certain fatty substances then called myelins. Mettenheimer published his observations in an obscure medical publication that soon passed out of existence, and along with it went Mettenheimer's observations. The work of Kaiserling and Orgler (6) brought about renewed interest in the doubly refracting phenomenon of certain fats and since that time, the polaromicroscope has been in common use in Germany. Adami (7) in 1906 emphasized the importance of this instrument in studying pathological fatty changes. At that time Adami felt that it was very useful in pathology, and that its value was underrated. Although the polarizing microscope was utilized to advantage by a few investigators in Europe, the use of it has not been widespread especially in America and England. Boyd (8) recently contended that the polaromicroscope has not received the recognition that it merits in biological work. He believes it is absolutely essential in researches upon lipoids, and that it is remarkable that it has not come into more general use. Although other methods of differentiating cholesterol esters from other fats are used, the doubly 
refracting phenomenon probably will always occupy an important place in such work, because of the simplicity of its recognition with the polarizing microscope. For the past two years, in connection with the work presented here, the polaromicroscope has been used routinely in examining kidney tissue removed or at autopsy. Urinary sediment, from all patients with any form of renal disease or heart disease, was examined routinely by this method. Despite the fact that the exact status of lipoids in Bright's Disease is not completely established, enough has been learned to insure them a place in clinical and research work of the future. Contrary to the general conception about it, the polaromicroscope is a simple device, and it seems that it is very useful in the clinical study of nephritis. In view of the fact that many particles in urinary sediment and in tissues are seen to shine brightly with the polariscope, it is better in diagnosis to rely upon the presence of the maltese crosses rather than upon the findings of particles with peculiar shades of brightness.

\section{DISCUSSION}

Why some cases of chronic glomerular nephritis have edema and others do not is an unsolved problem at present. Tubular degeneration is a part of the picture in all cases of diffuse glomerular nephritis. It is fair to assume that the glomeruli have been involved in so many cases of nephritis without edema, that they cannot be considered as the chief element in the cause of the edema. This would seem to be true, likewise, with the tubules, whose extensive involvement at times is not associated with edema. Opinions at present vary concerning the significance of chloride retention, plasma protein reduction and changes in the hydrophilic forces of the body colloids. Cholesterol, too, has been studied in a measure, clinically and experimentally, to determine its place in relation to the edema of nephritis. Port (9) was among the first to report a hypercholesterolemia in some case of chronic nephritis with edema. At about the same time Chauffard, Laroche and Grigaut (10) compared the cholesterol content of the blood in cases of cardiac and renal edema, and found an excess of cholesterol in blood of patients with nephritis and edema, while a normal amount was found in those with cardiac edema. They also stated that they studied six patients with chronic nephritis but edema 
free, whose nitrogen in the blood was greatly elevated and the cholesterol content of blood was normal or only slightly raised. In those patients where edema was most extensive, the cholesterol of the blood varied from 285 to 800 milligrams per $100 \mathrm{cc}$. They concluded that the patients who had the greatest nitrogen retention had the lowest cholesterol content in the blood. In addition to the observations on the quantities of blood cholesterol in nephritics, Kaiserling and Orgler, (6) drew attention to doubly refracting lipoids in kidneys of patients with amyloid disease. Later, Adami and Aschoff (11) proved that the doubly refracting globules, previously called myelin by Virchow (12) were, in fact, cholesterol esters. Munk (13) while studying the influence of anisotropic lipoids in kidney diseases, pointed out the importance of finding them in the urinary sediment. He believed the presence of lipoids indicated a poor prognosis. More recently Munk (14) studied the significance of lipoid in filtration and tubular degeneration. The hypercholesterolemia, in his opinion, is any expression of abnormal metabolism, and the tubular cell changes are secondary to constitutional alterations and changes in the blood itself. It is his belief that the kidneys are injured during the process of excretion of cholesterol subsequent to a hypercholesterolemia.

Epstein (15) states that the hypercholesterolemia is a change dependent upon a metabolic disorder of thyroid origin. He does not take up the question of lipoids in urinary sediment and in the tubular epithelium.

That cholesterol by itself in excessive quantities may be sufficient to injure and destroy tubular epithelium was shown by Dewey (4), who injected cholesterol intravenously into rabbits and caused lipoids to be deposited in the epithelial cells of the tubules.

On the relationship of nephritis to cholesterol metabolism Kollert and Finger (16) found that a hypercholesterolemia was not indicative of a defective excretory power of the kidney, because in cases where a reduction in kidney was present, a hypercholesterolemia did not follow. They suggested that the increase in the blood cholesterol is due to a change in the function of the liver which is secreting bile low in cholesterol content. In relation to edema, these authors believe that with the excretion of cholesterol by the kidney, the edema disappears and that the edema returns when the lipoids again are not ex- 
creted. Stepp (17) considering the hypercholesterolemia in cases of Bright's disease, suggested that in the nephritic conditions the cholesterol originates from fatty degeneration of the kidney, but he could not substantiate this opinion. Stepp carried out a study on the relation of blood cholesterol to different forms of Bright's disease. He made no report of polaromicroscopic examination of the urinary sediment or of the kidney tissues. Out of his 47 cases of acute and chronic Bright's disease, twelve died, and seven were examined post mortem. Those that showed a hypercholesterolemia had large smooth kidneys, with excessive disease of the tubular epithelium and marked edema. Kahn (18) found that the cholesterol was not invariably increased in parenchymatous nephritis, although it was increased at times in chronic interstitial nephritis.

It was the opinion of Henes (19) that the quantity of blood cholesterol could be used as a prognostic index, that a hypercholesterolemia was found in cases when the outlook was favorable, and a low cholesterol content when the prognosis was less favorable.

In a study of the lipoids in renal diseases, Daniels (20) found that the cholesterol of the blood was elevated in five out of seven cases of so-called chronic parenchymatous nephritis. Eleven other cases of various diseases of the kidney manifested no increase in blood cholesterol. He made no report of the presence or absence of urinary lipoids, but mentioned two cases in which lipoids were found in the tubules of sections removed from the kidney at time of decapsulation. Interesting also, was his observation that in only one case was there a decrease in blood cholesterol, when the urea nitrogen became elevated. Under the term "myelin kidney" M'Nee (21) described three cases, all of which showed glomerular nephritis with deposits of doubly refracting lipoids in the kidney tissues. Edema was noted in two cases but not mentioned in the other. He found that most of the lipoid substance was deposited in the interstitial tissue of the cortex. A smaller quantity was found in the epithelial cells of the convoluted tubules.

In a recent article, Lowenthal (22) considered clinically and experimentally the connection between blood cholesterol, blood proteins, and water balance. It seemed to him that the retention of lipoids paralleled the formation of edema and that the excretion of lipoids 
paralleled the excretion of water. With the retention of water and the hypercholesterolemia, a decrease in the serum proteins was found. Lowenthal, by feeding animals cholesterol, was able to produce a hypercholesterolemia with histological changes in the kidney tubules similar to those found in lipoid nephrosis in humans. He did not investigate whether or not a true hydremia was induced, although he says that he did not cause edema. He concludes that a hypercholesterolemia is caused by a primary change in lipoid metabolism and that there is consequently a deposit of lipoids in the renal tubular epithelium. He pointed out that the relationship between salt, protein, cholesterol and water balance has to be worked out as a future problem.

These findings were in conformity with those of Heilig and Lederer (23) who found a relative and absolute increase in the blood cholesterol in cases of nephritic edema, and that the degree of edema paralleled the height of the blood cholesterol. After a study of one hundred cases of nephritis, Bing and Heckscher (24) reported that the edema was associated with an elevation of the blood lipoids. They furthermore claimed that an increase of the fat in food leads to an increase in lipemia with a consequent increase of the edema.

In connection with this association of lipoid degeneration of the tubular epithelium, hypercholesterolemia and edema, Fahr (25) concludes that the kidney is not primarily at fault. For the development of edema, he believes certain alterations of the capillaries of the skin are necessary; that on the other hand the formation of an edema in nephritic cases shows a quite definite relationship to the increased deposits of cholesterol; and furthermore the reticulo-endothelial apparatus, and also that of the subcutaneous tissues, participates in cholesterol metabolism. Hence the conclusion that hypercholesterolemia and the cholesterol infiltration of the kidneys are expressions of those disturbances which produce alterations in the capillary walls of the skin and of the subcutaneous tissue and that edema occurs only after these alterations. While he holds that the glomerular change is always present, but that this is not sufficient in itself to produce the extensive edemas found, he points out that the tubules themselves are not solely responsible, since extensive tubular degeneration may occur without manifestations of edema and therefore he thinks that some extra-renal factor must be present. 
Cholesterol esters have been found deposited in the epithelial cells of the renal tubules by Weltmann and Biach (26) after they had fed a rabbit one gram doses of cholesterol daily for twenty-five days. Uranium nitrate was injected intra-peritoneally during the last seven days of the experiment. Control experiments without feeding cholesterol, but with injections of uranium nitrate, resulted in no lipoid deposits.

Chalatow (27) has shown that cholesterol esters are deposited in cells which have been injured, especially when acid products are formed in cells, and this causes the cholesterol esters to be deposited. $\mathrm{He}$ also found that a hypercholesterolemia could be produced in animals but that this in itself was not followed by cell infiltration. When the cells were poisoned, a very slight rise in cholesterol in the blood caused deposits of cholesterol ester in the injured cells.

A study of the association of glomerulo-tubular nephritis and nephrosis with edema was reported by Linder, Lundsgaard and Van Slyke (28). They dealt especially with the protein content of the plasma and its bearing on edema. It was concluded that there is no direct relationship of cause and effect between low protein concentration in the plasma and the presence and degree of edema. Furthermore, they pointed out that while fatty degeneration of the tubules is a conspicuous feature of the histological picture in nephrosis, and in nephrotic type of glomerular nephritis, it was found also in the tubules of those cases where little edema was found. They do not state, however, whether or not they differentiated between the doubly refracting lipoids and neutral fats. It would seem that had the urine been examined for doubly refracting lipoids in their cases of glomerular nephritis with nephrosis many would have been found.

In an article dealing with the pathology of nephritis associated with edema, Dyke (29) reported six cases of the type called by him chronic parenchymatous nephritis. Clinically, all were characterized by edema; histologically, by the presence of doubly refracting fat in the tubular epithelium. The glomeruli were impaired in all of the cases; in some only a degenerativ change with deposition of fat was seen, in some inflammatory signs were present and in others an amyloid degeneration was found. He called attention to the fact that it was not the degeneration of the tubular epithelium itself but the occurrence of lipoid deposits in them, that was of importance. 
The subject of relationship between lipoid degeneration of the tubules, hypercholesterolemia and edema is treated in an article by Bennet, Davies, and Dodds (30). They found that cases of renal edema, without hypercholesterolemia are conspicuously absent and they doubt whether such a condition occurs unless the edema is secondary to a failing heart. Among the unsolved problems, these authors included the significance of hypercholesterolemia to the edema in lipoid nephrosis, questioning whether it appears at the onset or follows a prolonged course of albuminuria.

It has been assumed usually, that the edemas of nephritis and nephrosis differ both in composition and pathogenesis. Epstein (31) has shown that the edema fluid of nephrosis is low in protein, while that of glomerular nephritis has a high protein content. He attributes the edema of glomerular nephritis to an increase of capillary pressure with increased filtration. The edema of nephrosis, he believes, is caused by a loss of plasma protein which is followed by an upsetting of the osmotic equilibrium between the blood and tissues which results in retention of water in the tissues.

It has been questioned whether the combination of chronic glomerular nephritis with secondary lipoid degeneration of the tubules in these cases constitutes an accidental association of two different diseases, or whether one is the result of the other. It has been emphasized by Elwyn (32) that the frequency of the occurrence of the combination of the two conditions seems too uniform to be accounted for by mere coincidence. The question that remains is why do some cases of glomerular nephritis remain free from lipoid changes and others exhibit them? While it is seen that attempts have been made to show parallelism between hypercholesterolemia and edema, the results have not been conclusive. Observations in this series of cases indicate that edema comes and goes irrespective of the height of blood cholesterol.

In the discussion of cases it is seen that patients may have a hypercholesterolemia with no edema and no doubly refracting lipoids in the urine. Chronic nephritic edema has been found to be invariably associated with a deposition of doubly refracting lipoids in renal tubules. That the co-existence of these symptoms and the deposition of cholesterol esters in the tubular epithelium is mere coincidence, 
seems untenable because of the constancy of their relationship in cases of chronic nephritis with and without edema.

One is led to conclude that it is neither the elevation of cholesterol in the blood alone nor the disease of the tubular epithelium alone, that exerts an influence upon the mechanism of edema production, but that the combination of diseased tubular cells and the presence in these cells of cholesterol esters, is the factor which seems to be connected with edema formation.

The histo-chemical analysis of the fatty substances of anisotropic character which I have mentioned and but briefly discussed has been omitted from this paper and is reserved for future detailed investigation. This clinical study is being continued and experimental investigation is being made of the problems here suggested.

\section{SUMMARY}

1. Thirty-one cases have been abstracted and discussed; fourteen had chronic glomerular nephritis with edema; eleven had chronic glomerular nephritis without edema, while six were cases of hypertensive cardiovascular disease with edema from cardiac failure. The cases are classed into three groups and the characteristic features of each group are discussed.

2. Emphasis has been laid on the fact that the presence of doubly refracting lipoids found in renal tubular epithelium and in the urinary sediment is associated with chronic nephritis and edema.

3. It was pointed out that doubly refracting lipoids were rarely found in the urinary sediment of patients with hypertensive cardiovascular disease with edema from cardiac failure (Group III).

4. None of the patients having nephritis without edema had doubly refracting lipoids in the urine and in none were they found in the tubular epithelium at autopsy.

5. A hypercholesterolemia was usually found in the cases of chronic nephritis with edema (Group I), while those cases of chronic nephritis without edema (Group II) and of hypertensive cardiovascular disease (Group III) usually had a normal cholesterolemia.

6. A chronic diffuse glomerular nephritis was present in all the cases of chronic nephritis described.

7. A review of some of the work done both clinically and experimentally upon the subject of cholesterol and nephritis is given. 
8. No theories have been advanced to explain these clinical observations as the clinical study is being continued and an experimental investigation is being made.

\section{BIBLIOGRAPHY}

1. Loeb, L., Medicine, 1923, ii, 171. Edema.

2. Murphy, F. D., and Warfield, Louis M., Arch. Int. Med., 1926, zxxviii, 449. Lipoid Nephrosis.

3. Christian, H. A., and O'Hare, James, The Oxford Med., 1920, iii, 583. Nephritis.

4. Dewey, K., Arch. Int. Med., 1916, xvii, 757. Experimental Hypercholesterolemia.

5. Mettenheimer, V., Quoted by Aschoff, L.: Lectures on Pathology. New York, P. Hoeber, 1924, p. 83.

6. Kaiserling, C., and Orgler, A., Virchows Arch. f. path. Anat., 1902, clxvii, 296. Ueber das Auftreten von Myelin in Zellen und seine Beziehung zur Fettmetamorphose.

7. Adami, J. G., Jour. Amer. Med. Assn., 1907, xlviii, 463. The Myelins and Potential Fluid Crystalline Bodies of the Organism.

8. Boyd, W., Brit. J. Surg., 1923, x, 337. Studies in Gall Bladder Pathology.

9. Port, F., Deutsch. Arch. f. klin. Med., 1910, xcix, 259. Die Saponinhämolyse und ihre Hemmung durch das Serum.

10. Chauffard, A., Laroche, G., and Grigaut, A., Compt. rend. Soc. de Biol., 1911, lxx, 108. Le Taux de la Cholestérinémie au Cours des Cardiopathies chroniques et des Néphrites chroniques.

11. Adami, J. G., and Aschoff, L., Proc. Roy. Soc. Lond., 1906, lxxviii, 359. On the Myelins, Myelin Bodies, and Potential Fluid Crystals of the Organism.

12. Virchow, R., Virchows Arch. f. path. Anat., 1857, xii, 101. Ueber die Erkenntniss von Cholestearin.

13. Munk, F., Zeitschrift f. klin. Med., Berl. 1913, lxxviii, 1. Klinische Diagnostik der degenerativen Nierenerkrankungen.

14. Munk, F., Pathologie und klinik der nierenerkrankungen. Berlin, 1925.

15. Epstein, A. A.: Amer. J. Med. Sci., 1922, clxiii, 167. Further Observations on the Nature and Treatment of Chronic Nephrosis.

16. Kollert, V., and Finger, A., Muench. Med. Wochenschrift, 1918, lxv, 816. Ueber die Beziehungen der Nephritis zum Cholesterin (Lipoid) Stoffwechsel.

17. Stepp, W., Deutsch. Arch. f. klin. Med., 1918, cxxvii, 439. Über den Cholesteringehalt des Blutes bei verschiedenen Formen der Bright'schen Krankheit.

18. Kahn, M., Arch. Int. Med., 1920, xxv, 112. The Protein and Lipin Content of Blood Serum in the Nephritides.

19. Henes, Edwin, Jr., Arch. Int. Med., 1920, xxv, 411. The Prognostic Value of Cholesterinemia in Chronic Nephritis. 
20. Daniels, W. B., Brit. Jour. Exper. Path., 1925, vi, 283. Plasma Lipoids in Renal Disease.

21. M'Nee, J. W., Jour. Path. and Bact., 1922, xxv, 425 . On Lipoid Degeneration of the Kidney, and the So-called "Myelin Kidney."

22. Lowenthal, K., Virchows Arch. f. path. Anat., 1926, cclxi, 109. Zur Frage der Lipoidnephrose.

23. Heilig, R., and Lederer, K., Klin. Wochenschrift, 1924, iii, 1765. Cholesterin und Wasserhaushalt.

24. Lowenthal, K., Virchows Arch. f. path. Anat., 1926, cclxi, 109. Zur Frage der Lipoidnephrose.

25. Fahr, T., Virchows Arch. f. path. Anat., 1922, ccxxxix, 32. Beiträge zur Frage der Nephrose.

26. Weltmann, O., and Biach, P., Ztschr. f. exper. Path. u. Therap., Berl., 1913, xiv, 367. Zur Frage der experimentellen Cholesteatose.

27. Chalatow, S. S., Die Anisotrope Verfettung im Lichte der Pathologie des Stoffwechsels, Jena., 1922.

28. Linder, G. C., Lundsgaard, C., and Van Slyke, D. D., Jour. Exp. Med., 1924, xxxix, 887. The Concentration of the Plasma Proteins in Nephritis.

29. Dyke, S. C., Quart. Jour. Med., 1924, xviii, 77. The Pathology of Nephritis Associated with Edema, as Illustrated by Six Cases.

30. Bennett, T. Izod, Davies, D. T., and Dodds, E. C., Lancet, 1927, i, 3. Studies in Renal Disease: "Lipoid Nephrosis."

31. Epstein, A. A., Amer. Jour. Med. Sci., 1917, cliv, 638. Concerning the Causation of Edema in Chronic Parenchymatous Nephritis: Method For its Alleviation.

32. Elwyn, H., Nephritis. New York, MacMillan Company, 1926.

\section{ABSTRACTS OF CASES: HISTORIES AND AUTOPSY FINDINGS}

\section{Group I. Patients with Chronic Nephritis and Edema}

Case 1. J. K., a white male, laborer, aged 50, entered the hospital on June 1, 1926, with the following history. He had always been in good health until about January 1, 1926, when he began to have severe morning headaches and his legs began to swell. The swelling varied in intensity but never entirely disappeared. On admission he was generally edematous. The heart was normal. The blood pressure was 180/110. Fundus examination: Optic neuritis in both eyes; discs swollen, hemorrhagic spots, atrophic areas about macula. Vessels tortuous. The function of the kidney was greatly reduced. Doubly refracting lipoids were found in the urinary sediment. On July 2, uremia set in and he died the next day.

Diagnosis: Chronic diffuse glomerular nephritis with secondary lipoid degeneration of the tubules.

Case 2. F. P., aged 40 was admitted to the hospital on January 16,1927 , with the following complaint. Six weeks before, his face and legs became swollen to 
such a degree that he was forced to quit his work. The blood pressure was 260/ 154. Aside from a moderate enlargement, the heart was normal. The lungs were normal; considerable ascites was present; the liver was palpable but not painful and the scrotal sac was filled with fluid. A few doubly refracting lipoids were found. The renal function was greatly reduced. Ophthalmoscopic examination: Discs markedly swollen and edematous. Retina had many hemorrhages. Veins were very tortuous and distended; it was impossible to see vessels throughout their course due to eđema of retina. This patient left the hospital on the fourth day after entrance.

Diagnosis: Chronic diffuse glomerular nephritis, with secondary lipoid degeneration of the tubules.

Case 3. S. C., a negress, aged 24 , entered the hospital on July 14, 1926, complaining of sore throat, violent headache, nausea, vomiting and dyspnea. She had had an attack of tonsillitis in 1922 after which edema, headache and bloody urine developed, and she was confined to bed for seven weeks. About July 19, 1926, she had another attack of sore throat, again followed by edema, vomiting and the other symptoms. Physical examination: She was well developed, considerably swollen, quite stuporous, and had a blood pressure of 210/130. Many doubly refracting lipoids were found in the urinary sediment. The renal function was reduced to a very low level. She went into uremic coma and died on August 10, 1926. Autopsy findings: A pair of white, coarsely granular kidneys were found, the right one weighing 56 grams, the left 75 grams. The capsule was adherent to the cortex and stripped with difficulty. The cortex was thinned. The cortex and columns of Bertini were pale with a tinge of yellow similar to that seen in pure lipoid nephrosis. The peripelvic fat was less than normal. On microscopic examination many glomeruli were completely obliterated, others were partially destroyed by fibrous tissue proliferations. Extensive fibrosis was seen. In some areas there was an increase of cells, with exudate in the capsular spaces. With fat stains large quantities of fat were found in the tubular epithelium of the convoluted tubules and in the interstitial tissue. Some of the fat was anisotropic. The tubular epithelium was universally degenerated.

Diagnosis: Chronic diffuse glomerular nephritis with secondary lipoid degeneration of the tubules.

Case 4. F. W., a white male, aged 36, a salesman, was seen for the first time on April 3, 1926. His chief complaints, general edema and headaches, were of several months standing. There was considerable edema of the entire body. The heart's action was normal. The blood pressure was $230 / 140$. On polariscopic examination many doubly refracting lipoids were found in the urine.

Diagnosis: Chronic diffuse glomerular nephritis with secondary lipoid degeneration of the tubules. 
Case 5. F. S., aged 34, a foreman in a factory, was first seen on May 9, 1926. He complained of generalized dropsy, severe occipital headaches, and epistaxis for the past three months. At the age of 19, he had an attack of scarlet fever, followed by acute glomerular nephritis, symptoms of which lasted for four months. He was quite well until three months before coming under observation. Physical examination: There was a generalized anasarca. The heart was enlarged to left. The blood pressure was 208/130 during the time he was under treatment. On every examination many doubly refracting lipoids were found in the urine. Renal function was greatly impaired. He died in uremia on June 14, 1926. Autopsy findings: The heart weighed $\mathbf{4 2 0}$ grams. There was a left ventricular hypertrophy. Both kidneys were larger than normal, the right one weighed 185 grams, the left 163 grams. Both were pale; the surfaces were mottled. On section the cortex was found thicker than normal and presented a fatty appearance, not unlike that seen in pure nephrotic cases. The capsule stripped easily though in places it was adherent to the cortex. Microscopically: A considerable increase in the fibrous tissue was found. Practically every glomerulus showed signs of inflammation. Hyalin necrosis of many capillary loops was found. The epithelial cells lining the convoluted tubules were swollen and many had undergone disintegration. With Scharlach $\mathrm{R}$, large quantities of fatty material were found in the epithelial cells of the tubules, especially of the distal convoluted tubules. Some of this fat was found to be doubly refracting.

Diagnosis: Chronic diffuse glomerular nephritis with secondary lipoid degeneration of the tubules.

Case 6. S. S., a white female, aged 23, was seen for the first time on October 4, 1926. The chief complaints were swelling of the face and ankles and shortness of breath. On September 1, 1926, she began to have edema of the ankles and headache. Physical examination: The edema about the eyes and ankles was well developed. The pulse was regular and full and the radial vessels were not thickened. The heart and lungs were normal. The blood pressure was 170/105. Doubly refracting lipoids were constantly present in the urine. Renal function was slightly decreased.

Diagnosis: Chronic diffuse glomerular nephritis with secondary lipoid degeneration of the tubules.

Case 7. F. K., a white male, laborer, aged 39, entered the hospital on June 30, 1925. Two months previous to entrance, for the first time in his life he had swelling of the face and ankles. The edema gradually progressed to general anasarca. The heart and lungs were normal; the blood pressure was $185 / 110$. Doubly refracting lipoids were found in the urinary sediment. Renal function was seriously impaired. There was no remission in the course of the disease, and on July 23, 1925 he died in uremic coma.

Diagnosis: Chronic glomerular nephritis with secondary lipoid degeneration of the tubules. 
Case 8. J. D., a boy aged 13, entered the hospital on November 6, 1925, with the following history: About two weeks before entrance a sore throat developed with swelling of the lymph glands on both sides of the neck. After two weeks edema of the face was noticed. Within a few days there was a general anasarca. The blood pressure was 118/60. Renal function was slightly reduced. Many doubly refracting lipoids were found in the urinary sediment. The edema disappeared gradually; the urine continually showed doubly refracting lipoids. For the two years that this patient has been under constant supervision, doubly refracting lipoids have always been present in the urine. At intervals the edema was developed with other findings of glomerular nephritis.

Diagnosis: Chronic glomerular nephritis with secondary lipoid degeneration of the tubules.

Case 9. S. W., a white male, aged 42 , laborer, was admitted to the hospital for the last time on December 4,1925. He had been in the hospital a number of times since 1923. Chief complaint: For the past four months he had been suffering from shortness of breath, pain in the back, headache and dropsy. The dyspnea came and went; the edema, though it fluctuated in intensity, persisted throughout the illness. The past history was unimportant. The blood pressure was $210 / 140$. The heart was greatly enlarged. Renal function was moderately reduced; a hypercholesterolemia was present. Autopsy findings: The heart weighed 728 grams; the left ventricle was unusually hypertrophied. The valves were practically normal. Slight sclerosis of the aorta around the coronary ostia was present but the lumina were patent. Fluid was found in the pericardial, peritoneal, and pleural cavities; general anasarca was present. Both kidneys were slightly smaller than normal and red in color. The right weighed 135 grams the left 129 grams. The capsule stripped with ease, leaving a finely granular surface. Some granules were composed of yellowish deposits. On sections the cortex was thinner than normal, but the markings of the kidneys appeared normal. Microscopically: There was a selective tubular degeneration. Stained with Sudan 3 fresh sections showed a fatty deposit confined to the proximal envoluted tubules and the collecting tubules. Many of the convoluted tubules, both proximal and distal, contained doubly refracțing lipoids. Intracapillary as well as capsular glomerulitis was present. The interstitial tissue was moderately increased. Diagnosis: Chronic diffuse glomerular nephritis with secondary lipoid degeneration of the tubules.

Case 10. J. Y., a white male, aged 29, was admitted to the hospital on January 18,1927 , complaining of swollen legs, arms, face and chest. The trouble began one month before entrance to the hospital; he had no other complaint and had had no trouble of any kind before the onset of the present illness. Other than for a soft mitral systolic murmur the heart was normal. Ascites and general anasarca were present. The eye grounds were normal. The blood pressure was 145/95. Many doubly refracting lipoids found in the urine. After one week the edema 
disappeared and the patient felt very well. Diagnosis: Chronic glomerular nephritis with secondary lipoid degeneration of the tubules.

Case 11. G. K., a white male, aged 22, was admitted to the hospital on August 10,1925 complaining of cough, shortness of breath and dropsy. About two months previous to admission to the hospital a generalized anasarca developed. Physical examination: Edema and dyspnea were present. The heart was normal. Radial vessels were normal. Some fuid was present in the abdominal cavity and in the scrotal sac. The lungs were normal with the exception of râles in both lower lobes. The blood pressure was $165 / 110$. Many doubly refracting lipoids were found in the urinary sediment. Renal function was decidedly reduced. The eye grounds showed an albuminuric retinitis. He died in uremic coma on November 30,1925. Diagnosis: Chronic diffuse glomerular nephritis with secondary lipoid degeneration of the tubules.

Case 12. F. K., a white male, aged 55, entered the hospital December 22, 1926, complaining of shortness of breath, edema of face and legs and headaches. The edema although present on and off for the past year and one-half had been persistent and considerably increased during the past three months. The heart was found to be moderately enlarged, and somewhat more rapid than normal, but otherwise was not abnormal. The blood pressure was 240/140. Palpation of the radial vessels revealed some thickening. No doubly refracting lipoids were found. The renal function was greatly reduced. He developed an asthenic type of uremic coma and died on January 18, 1927. Autopsy findings: The heart weighed 500 grams. The valves were normal. The left ventricular wall was increased in size. Both kidneys were greatly contracted, the right kidney weighing 41 grams, the left 64 grams. There was a most unusual coarseness to the surface of both kidneys. The capsule was removed with considerable difficulty and portions of the cortex adhered to the capsule. On sectioning, the peri-pelvic fat was increased. The cortex thinned and the demarcation between cortex and medulla was in places not clearly defined. Histologically, the glomeruli showed intra-capillary as well as extra-capillary glomerulitis. Considerable interstitial fibrosis was seen. Arteriosclerosis was widespread. The tubular epithelium was gone in some places, in others greatly swollen and degenerated. With Sudan 3 a large amount of fat was found in the tubular epithelium, and many doubly refracting lipoids were found in the distal and proximal convoluted tubules. Diagnosis: Malignant hypertension (renal type) with secondary lipoid degeneration of the tubules.

Case 13. J. C., a white male, aged 40 years, entered the hospital for the first time on October 25, 1924, complaining of swollen legs and pain in the small of the back for five months. Physical examination: Generalized edema present. The heart was normal with the exception of a greatly accentuated aortic sound. Ascites was present; the scrotal sac was distended with fluid. Eye grounds exami- 
nation showed a papillitis with hemorrhages in the right eye and to a lesser degree in the left. The blood pressure was 220/120. He left the hospital but re-entered on February 5, 1925. Doubly refracting lipoids were found in abundance in the urinary sediment. On December 15, 1925, he began to have uremic convulsions and died in uremic coma Decemter 18, 1925. Autopsy findings: (partial). The kidneys were larger than normal, the right one weighing 156 grams, the left 163 grams. The surface was smooth and there was a diffuse yellowish tinge throughout the cortex and columns of Bertini. The markings between the cortex and medulla were well preserved. Microscopically: Many doubly refracting lipoids were distributed rather evenly throughout the convoluted tubules, descending loops of Henle and in the interstitial tissue. None was found in the glomeruli. The glomeruli were universally diseased; an intra-capillary glomerulitis with swollen tufts characterized the picture, many glomeruli were fibrosed and hyalinized. The blood vessels appeared normal.

Diagnosis: Chronic diffuse glomerular nephritis with secondary lipoid degeneration of the tubules.

Case 14. A. L, a white female, aged 30, was first seen on October 6, 1926, complaining of edema, dizziness and headache. She had an attack of acute glomerular nephritis in 1921. She remained quite well from 1921 until the present attack came on. The heart was normal. The blood pressure was 220/110. The radial arteries were thickened. Renal function was reduced. A hypercholesterolemia was present. On January 29, 1927 uremic coma developed and she died the next day.

Diagnosis: Chronic glomerular nephritis with secondary lipoid degeneration of the tubules.

\section{Group iI. Patients with Chronic Nephritis and no Edema}

Case 15. C. G., a white male, aged 58, entered the hospital on February 5, 1927, on account of headache, cough, dizziness and great weakness. For two months previous to entrance he had been suffering from polyuria and headaches. On the day of entrance he began to have twitching about the mouth and arms. Uremic coma and a bilateral broncho-pneumonia developed. The heart was slightly enlarged. The radial vessels were thickened, tortuous, and calcified. The blood pressure was 180/112. There was no edema and no history of any. No doubly refracting lipoids found. Renal function greatly impaired. He died of uremia on February 7, 1927. Autopsy findings: (partial): Both kidneys were surrounded by a mass of fat. They were smaller than normal-the right weighed 118 grams, the left 110 grams - and on peeling of the slightly adherent capsules a finely granular cortex was seen. On section, the cortex was found very thin in places; the interstitial tissue increased. The peripelvic fat was increased. Throughout the kidney as well as the hilum, the vessels were thickened and stood out prominently. Microscopic examination: The tubular epithelium was uni- 
versally degenerated. Fat was found with Sudan 3 in the renal tubular epithelium and in the walls of many arterioles. No doubly refracting lipoids were found. Many glomeruli were completely obliterated, others were undergoing fibrosis and hyalinization. Glomerular crescents were numerous and fibrosis tissue proliferation around the capsules was prominent. A generalized arteriosclerosis was found.

Diagnosis: Chronic diffuse glomerular nephritis.

Case 16. P. A., aged 31, white female, was first seen on October 17, 1926. The chief complaints were severe headaches, blurring of vision, and loss of weight and strength with polyuria and nocturia. Except for scarlet'fever at the age of eight, the past history was negative. During September 1925, she was taken with severe headaches which would persist for days at a time. A few months later her vision began to be affected. Examination: The pulse was hard and a palpable whipcord radial was felt. The heart was moderately enlarged and the heart sounds were of good quality. The lungs and abdomen were normal. The blood pressure was 250/150. No doubly refracting lipoids were found. Renal function was gravely impaired. Eye ground examination showed an albuminuric retinitis. A fibrinous pericarditis developed on October 23, 1926. She died on October 25, 1926. No edema developed.

Diagnosis: Chronic diffuse glomerular nephritis.

Case 17. W. H., a white male, aged 52, entered the hospital on the first of December 1926, complaining of polyuria, visual disturbances, dyspnea, and headache. The present trouble began three months before entrance. Except for the fact that his father died of "Bright's disease" the family history was negative. He had had hypertension for 5 years. Physical examination: The patient was a thin muscular man who seemed very restless and distressed. The abdomen, genitalia, extremities and lungs were quite normal. The heart was enlarged; the left heart border was palpated $1 \frac{1}{2}$ inches outside the left nipple line. The radial vessels were thickened but not calcified. The heart sounds were strong. There was no edema. The blood pressure was $188 / 126$. Renal function greatly depressed. Ophthalmoscopic exannination disclosed old as well as recent retinal hemcrrhage. The vessels were sclerotic. He died of uremia on December 25, 1926. Autopsy findings: Both kidneys were contracted; the right one weighed 112 grams, the left 100 grams. The capsules stripped with difficulty, and left a finely granular surface. The peripelvic fat was not increased; the marking between the cortex and medulla was obliterated in places. The cortex was thinned. Histologically the glomeruli were all diseased; some showed evidence of recent and some of old inflammations. The arteriolar walls were unusually thickened; in places complete atresia of the lumen was found. The tubules were uniformly diseased. Sections were stained for fat but none was present. No doubly refracting lipoids found.

Diagnosis: Malignant hypertension (renal type). 
Case 18. C. R., white male, aged 25, entered the hospital on October 23, 1926, complaining of dizainess, backache, polyuria, nocturia and weakness. He had always been well until the age of 19 , when he suffered from chorea followed by endocarditis and pericarditis. He recovered within the year and continued to work until he was incapacitated by the present illness in October 1926. Examination: There was no edema. Blood pressure 190/116. He had a chronic adhesive pericarditis. No doubly refracting lipoids were found. Eye grounds were practically normal. Renal function was moderately reduced. The cholesterol was elevated.

Diagnosis: Chronic diffuse glomerular nephritis.

Case 19. R. O., a white male, aged 50, was admitted into the hospital March 3,1926 , with dyspnea, edema of the lower extremities and ascites. He has been quite well until about January 1,1926 , when he was taken with shortness of breath, cough and dropsy. The edema here was considered to be the result of cardiac failure. The heart was excessively enlarged and a mitral systolic murmur was heard. No irregularity was present. There was considerable thickening of the radial vessel walls and some calcification was found. No doubly refracting lipoids found. Renal function was reduced. He died of pneumonia (lobar) October 16, 1926. Autopsy finding: The heart weighed 668 grams; the left ventricle was greatly hypertrophied. Old negative lesions involved the mitral valve. Coronaries more considerably thickened and calcified, partially occluding the orifices. Both kidneys appeared smaller than normal. The right weighed 142 grams, the left 154 grams. They were finely granular; in appearance the granules being irregular in sice and gradually disappearing in the region of the pelvis; there was an occasional atrophic depression. On section the cortex was congested and close above several pyramids it exhibited a yellowish crescent-shaped thin area. The pyramids were pale. All the visible smallest blood vessels were stiff and gaping. The peripelvic and perirenal fat tissue was increased. Microscopically: No fat was found in the tubular epithelium. Many glomeruli were completely fibrosed, many others showed capsulitis and increase of intracapillary cells. Arteriolar walls were universally thickened. No doubly refracting lipoids found.

Diagnosis: Malignant hypertension (renal type).

Case 20. A. N., a white male, 42, entered the hospital on October 26, 1924. He complained of severe headaches, epistaxis, dizziness, vomiting and insomnia for the past four months. The blood pressure was 240/150. On ophthalmoscopic examination a disseminated choroiditis was found. The heart was enlarged, rapid, but regular in action. There was no edema. Kidney function was greatly reduced. Radial vessel walls uniformly thickened. No doubly refracting lipoids found. He died in uremic coma on January 11, 1925. Autopsy findings: The heart weighed 462 grams and left ventricle was exceedingly hypertrophied. Examination of the valves and coronary arteries revealed no abnormalities. Both kidneys were contracted and granular, and the capsule stripped with difficulty. 
Right kidney weighed 125 grams, the left 118 grams. The cortex was very thin and there was an increase of fibrous tissue. Microscopically: Many glomeruli were completely fibrosed; evidences of capsulitis and intracapillary glomerulitis were present. Hyaline necrosis of capillary loops found. In the lumen of the tubules were found many desquamated epithelial cells and blood cells. The tubular epithelium was diffusely degenerated. Considerable fat was found with Sudan 3 in the tubular walls in the interstitial tissue, and around the walls of arterioles. None of this fat was anisotropic.

Diagnosis: Chronic diffuse glomerular nephritis.

Case 21. R. McF., a white male, aged 52, was admitted to the hospital on July 26,1926, complaining of headache, dyspnea and palpitation of the heart. Until the onset of the present trouble, he had always been well. Examination: Blood pressure 230/100. The heart was enlarged to the left, an apical systolic murmur transmitted to axilla was heard. There was no edema, the radial blood vessel walls were greatly thickened but no calcification was present. Ophthalmoscopic examination showed an increase in light reflex of the arteries, hemorrhages old and recent were present. No doubly refracting lipoids were found. The renal function was reduced. On December 16, 1926, he died of apoplexy. Autopsy findings: Unfortunately permission for examination of the brain was not given. The heart weighed 565 grams. Left ventricular hypertrophy was marked. Valves normal. Both kidneys were decidedly contracted and coarsely granular; the right one weighed 94 grams, the left 102 grams. By stripping away the capsule some portions of the cortex were removed. The peripelvic fat was greatly increased. In places the demarcation between cortex and medulla could not be seen; the cortex was remarkably thinned. Microscopically, many areas of cellular infiltration were seen, the glomeruli were greatly diseased; extra capillary glomerulitis was present, hyalin necrosis of many capillary loops found; extensive fibrous obliteration of glomerular vessel walls moderately fibrosed. No fat found in the tubules with fat stains, and no doubly refracting lipoids were found.

Diagnosis: Chronic diffuse glomerular nephritis.

Case 22. G. L., a white male, aged 36, entered the hospital on February 24, 1925, complaining of blurring of vision and vomiting and occipital headaches for the past month. At the age of 24 , he contracted scarlet fever, which kept him confined to bed for eight weeks, but he said that he had no kidney trouble at that time. The patient was a thin anemic looking man without edema. The hear $\mathrm{t}$ was enlarged to left, was regular in action and no murmurs were made out. The lungs, abdomen and genitalia were normal. The blood pressure was 185/100. No doubly refracting lipoids were found. The blood cholesterol was not elevated. There was a profound reduction in renal function. On February 28, 1925, four days after entrance, a fibrinous pericarditis and uremia developed and he died. Autopsy findings: The heart weighed 315 grams; fibrinous pericarditis found. Both kidneys were surrounded by fat tissue that was firmly adherent to the upper 
half of each organ. The right kidney weighed 149 grams, the left 155 grams. The surface of the kidneys was granular and the cortex thin. On section the cortex was congested. The capsule was thickened and adherent to the surface. Microscopic examination: The uriniferous tubules were compressed and many were destroyed. There was a cellular infiltration into the interstitial tissue. The Malpighian bodies varied greatly in size and shape. Many were hyalinized, others partially fibrosed. The tubules contained both red cells and leukocytes and in places organized casts. No fat was present in the tubular epithelial cells. No doubly refracting lipoids found.

Diagnosis: Chronic diffuse glomerular nephritis.

Case 23. L. J., a white male, aged 32, was admitted to the hospital on November 11, 1925, complaining of headache. The blood pressure was 240/150; the heart was slightly enlarged, otherwise normal. No edema was present. Ophthalmoscopic examination revealed old retinal hemorrhgaes but no recent one. No doubly refracting lipoids present. Renal function was greatly decreased. He was under observation until death in September 1926. Edema never developed. Uremia with plastic pericarditis terminated the course of the disease on September 15, 1926. Autopsy findings: The heart weighed 318 grams, the left ventricular wall was greatly hypertrophied. Plastic pericarditis present. Right kidney weighed 62 grams, the left one 55 grams. The capsules were adherent to the cortex. Both kidneys were coarsely granular in type. The cortex was very thin and in places the demarcation between cortex and medulla was obliterated. Microscopically, the fibrous tissue throughout the kidney was increased. A capsular as well as an intracapillary glomerulitis was universal. Areas of cellular infiltration numerous. The tubules showed evidence of degenerative changes. No doubly refracting lipoids present, and no fat was found with fat stains.

Diagnosis: Chronic diffuse glomerular nephritis.

Case 24. D. D., a white female, aged 47, entered the hospital on January 17, 1927 , complaining of dyspnea, cough, headache and vomiting for the past year. The blood pressure was $205 / 142$; the heart was enlarged to the left and rapid. The radials were thickened but not calcified. Renal function was greatly reduced. No doubly refracting lipoids found. Coma developed and she died on February 2, 1927. Autopsy findings: The heart weighed 308 grams. There was a remarkable hypertrophy of the left ventricular wall. The coronary arteries were patent, but moderate sclerosis was found. Both kidneys were coarsely granular and contracted, the right one weighed 105 grams, the left the same. The capsule stripped with considerable difficulty. On section the cortex was thinned and an increase in interstitial tissue could be seen. The walls of the smaller vessels were thickened and stood out prominently. Microscopically: Practically every glomerulus was diseased. Many had undergone complete fibrosis; extensive capsulitis as well as intracapillary inflammation was seen. Areas of cellular increase were numerous. The epithelium of the tubules was extensively degenerated. Moder- 
ate amount of fat was found with Sudan 3 in the epithelium of the convoluted and straight tubules. No doubly refracting lipoids found.

Diagnosis: Chronic diffuse glomerular nephritis.

Case 25. M. J., a white female, aged 40, entered the hospital on January 28, 1927, complaining of nervousness, visual disturbances and nocturia. The heart was enlarged. The walls of the radials were practically normal. The blood pressure was 260/136. There was no edema. No doubly refracting lipoids found. Autopsy findings: There was no cerebral hemorrhage. Both kidneys were very small and hard in consistence. The right weighed 75 grams, the left 83 grams. Their surface showed a diffuse granular appearance, the granules being regular in size and less pronojunced toward the hilus of the organs. On the cut surface the cortex appeared thin; the vessels were gaping. The peripelvic fat tissue was increased. Microscopically: The glomeruli in places showed an increase in the number of nuclei and thickening of the Bowman's capsule; in places the glomeruli were completely fibrosed. A diffuse round cell infiltration of the interstitial tissue was found. No fat found with fat stains and no doubly refracting lipoids found.

Diagnosis: Chronic diffuse glomerular nephritis.

\section{group iIr. Patients with Hypertensive Cardiovascular Disease with Cardiac Edema}

Case 26. D. N., a white male, aged 51, was first examined on October 2, 1925. He had been complaining of headaches, dyspnea and swollen ankles for the past year. The radial arteries were considerably thickened, tortuous, and hard to compress. The left heart border was found in the anterior axillary line. There were no murmurs nor evidences of fluid. The aortic second sound was greatly accentuated. A tendency to gallop rhythm was present. Blood pressure 215/124. Examination revealed extensive edema, ascites, pleural effusion and some pericardial effusion. No doubly refracting lipoids were found on many examinations.

Diagnosis: Hypertensive cardiovascular disease.

Case 27. M. G., a white female, aged 54, entered the hospital on July 8, 1926, complaining of precordial distress, dyspnea, swollen arms and legs. The trouble began five years previously when shortness of breath and weakness caused her to give up her occupation. The blood pressure, at that time, she said was over 200. The radial artery walls were greatly increased in thickness and were tortuous. Ascites was present with generalized edema. The heart was greatly enlarged and the sounds were muffled, weak and rapid. The blood pressure was 242/130. The condition of the patient remained about the same, except for short periods of improvement until she died of heart failure on September 5, 1926. Autopsy findings: The heart weighed 585 grams. The walls of the left ventricle were greatly thickened. The mitral valve was not of an old rheumatic endocarditis. The 
right kidney weighed 128 grams, the left 122 grams. Both kidneys were coarsely granular in appearance; and were contracted. The capsule was slightly adherent On section the cortex was found quite thin and the interstitial connective tissue was increased. The normal markings of the kidneys were practically obliterated. Many of the larger and smaller arteries stood out conspicuously and their walls were unusually thickened. The peripelvic fat was abnormally increased. Microscopically, many glomeruli were normal, others enlarged, while some were completely fibrosed. Hyalin degeneration of the intima of many of the smallest arterioles was found with many glomeruli partially hyalinized and fibrosed. With Scharlach R, some fatty material was found scattered throughout the epithelial cells of many of the convoluted and straight tubules. None of this fat was found to be doubly refracting.

Diagnosis: Hypertensive cardiovascular disease.

Case 28. W. H., a white male, aged 48, entered the hospital on February 12, 1926. His blood pressure had been elevated for the past year, but the present trouble began a month before entrance. He was dyspneic, orthopneic, edematous and cyanotic. The walls of the radial arteries were extensively thickened, and felt like solid cords to the palpating fingers. Blood pressure 210/106. The left ventricle was exceedingly hypertrophied. The heart sounds were distant and weak. A systolic mitral murmur was present. Chronic hypertrophic emphysema as well developed. Edema of the extremities as well as ascites was present. Renal function was depressed. No doubly refracting lipoids were found in the urinary sediments. Improvement followed treatment.

Diagnosis: Hypertensive cardiovascular disease.

Case 29. J. M., a white male, aged 50, entered the hospital on February 15, 1926. He had known that his blood pressure was over 200 for the past three years and that the urine had been free from albumin. About two months before entrance he began to have swollen legs and was dyspneic. The walls of the radials were considerably thickened and tortuous, but no calcification was found. There was an enormous scrotal edema, as well as extensive edema of the lower extremities. On examination the left heart border was found well outside the nipple line. Some irregularity of rhythm was present, and the heart sounds were muffled due to accumulation of pericardial fluid. Renal function was moderately reduced. Examination of the urinary sediment with the polaromicroscope occasionally revealed a few doubly refracting lipoids.

Diagnosis: Hypertensive cardiovascular disease.

Case 30. B. M., a white male, aged 46, entered the hospital on January 8, 1927. In 1917 when examined for army service he was refused admission because the blood pressure was over 200 , and his heart was enlarged. He had very little trouble until November 1926 when his feet began to swell and dyspnea set in. These symptoms steadily progressed until he came to the hospital. Blood pressure 
$218 / 100$. The walls of the radial were definitely thickened, but no tortuosity or calcification made out. The left side of the heart was greatly hypertrophied. There was considerable edema of the lower extremities with a moderate degree of scrotal dropsy. No ascites was present. Renal function was reduced. No doubly refracting lipoids were found. Although heart failure was pronounced he died suddenly on May 19, 1927 of pulmonary embolism. Autopsy findings: The heart weighed 613 grams. No valvular disease present. Aorta widened otherwise normal. Thrombi were found in the right auricular appendage. An embolus was found in a branch of the left pulmonary artery. Both kidneys were enlarged and smooth. The right weighed 198 grams, the left 186 grams. The capsule stripped easily. On section the cut surface seemed normal, except that the wall of many small arteries were seen to be thickened. Histologically, many glomeruli were completely fibrosed, others partially fibrosed and hyalinized. The tubular epithelium was swollen in places. The walls of smaller arterioles were excessively thickened and lumen of some was almost occluded. With fat stains no fatty material was seen. No doubly refracting lipoids were found.

Diagnosis: Hypertensive cardiovascular disease.

Case 31. L. D., a white female, aged 44, had had high blood pressure and shortness of breath for the past year. She entered the hospital on November 7, 1926 with pronounced general amasarca and dyspnea. The walls of the radial and other accessible arteries were very thick. There was considerable cardiac enlargement to the left. Blood pressure 196/115. Some free fluid was found in the abdomen and in both pleural cavities. No doubly refracting lipoids found in the urine. Renal function was reduced. She died of heart failure on March 3, 1927. Autopsy findings: The heart weighed 497 grams. Evidences of an old endocarditis were found on the mitral valve and aortic valves. Both kidneys were contracted, the right weighed 112 grams, the left 107 grams. The capsule stripped with some difficulty, leaving a finely granular surface. On section the peripelvic fat was found greatly increased. The cortex was thin and the interstitial connective tissue was increased to such degree that the marking between cortex and medulla was hard to make out. Many of the smaller arteries stood out; it could be seen that their walls were greatly increased in thickness. Microscopically, many glomeruli were hypertrophied and the lumens of the tubules in places were widened. There was a definite fibrosis of many of Bowman's capsules, and many glomeruli were obliterated by connective tissue. Other glomeruli were normal. The tubular epithelial cells were swollen but otherwise normal. The chief finding was the extensive thickness of the smaller blood vessel walls with atresia of their lumen in places. With Scharlach R, a small amount of fatty material was found in the epitheial cells of a few of the convoluted and straight tubules also some was found in the intertubular tissue. None of this fat was doubly refracting.

Diagnosis: Hypertensive cardiovascular disease. 


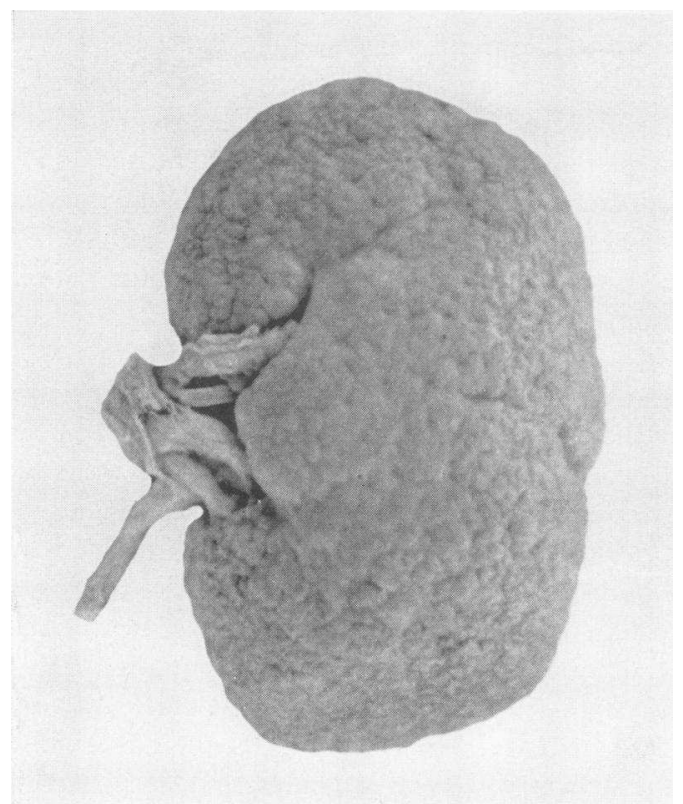

Fig. I. Case 3. Left Kidney (Natural Size), Showing the Uniformly Granular Surface and Contraction of the Organ 


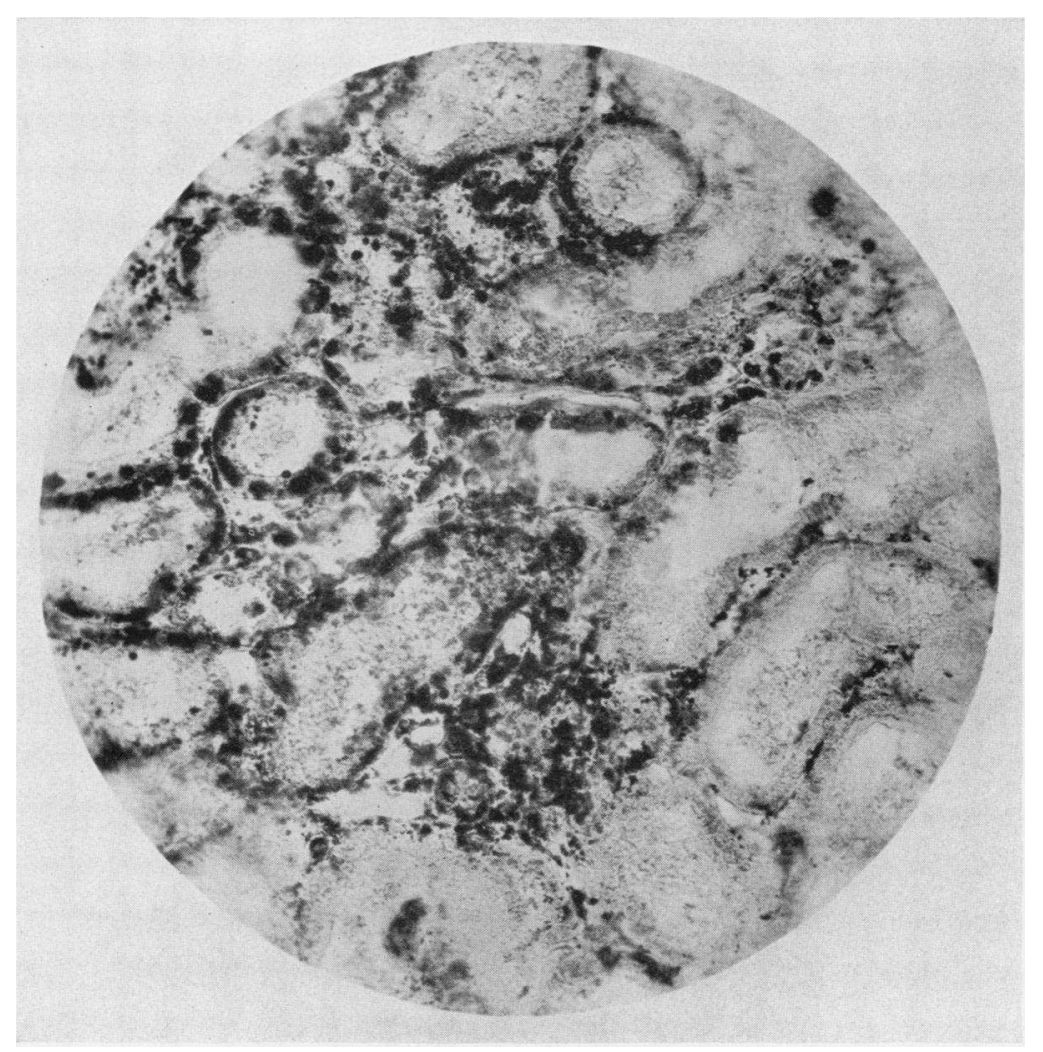

Fig. II. Case 3. Area Showing Extensive Deposits of Lipoid Substances IN the Tubular Epithelium and to a Lesser Extent In the INTERstitial Tissue; Section Stained with Sudan III; $\times 700$ 


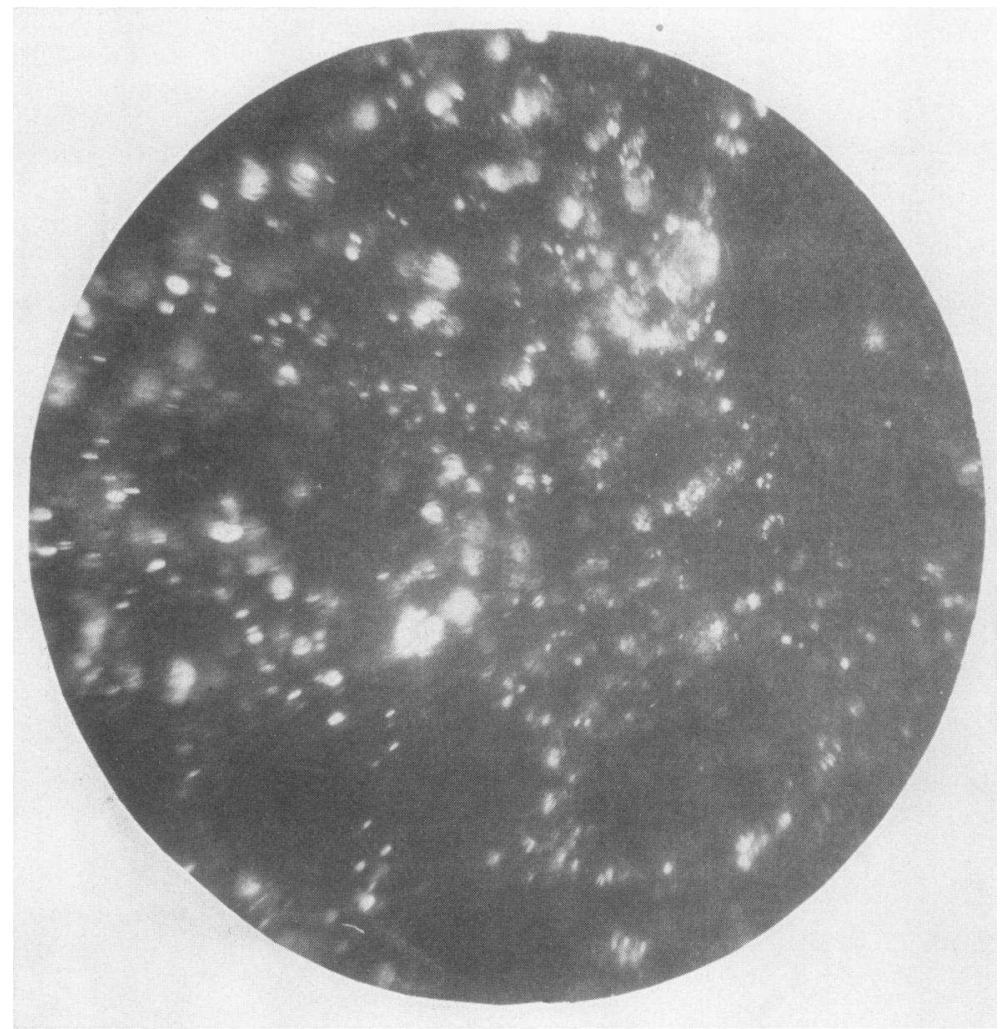

Fig. III. Case 3. Section of an Area Similar to That in Figure II

The tissue is unstained and observed under crossed Nicol's; the doubly refracting substances (lipoid) are in both the tubular cells and the interstitial tissue; $\times$ 700 . 


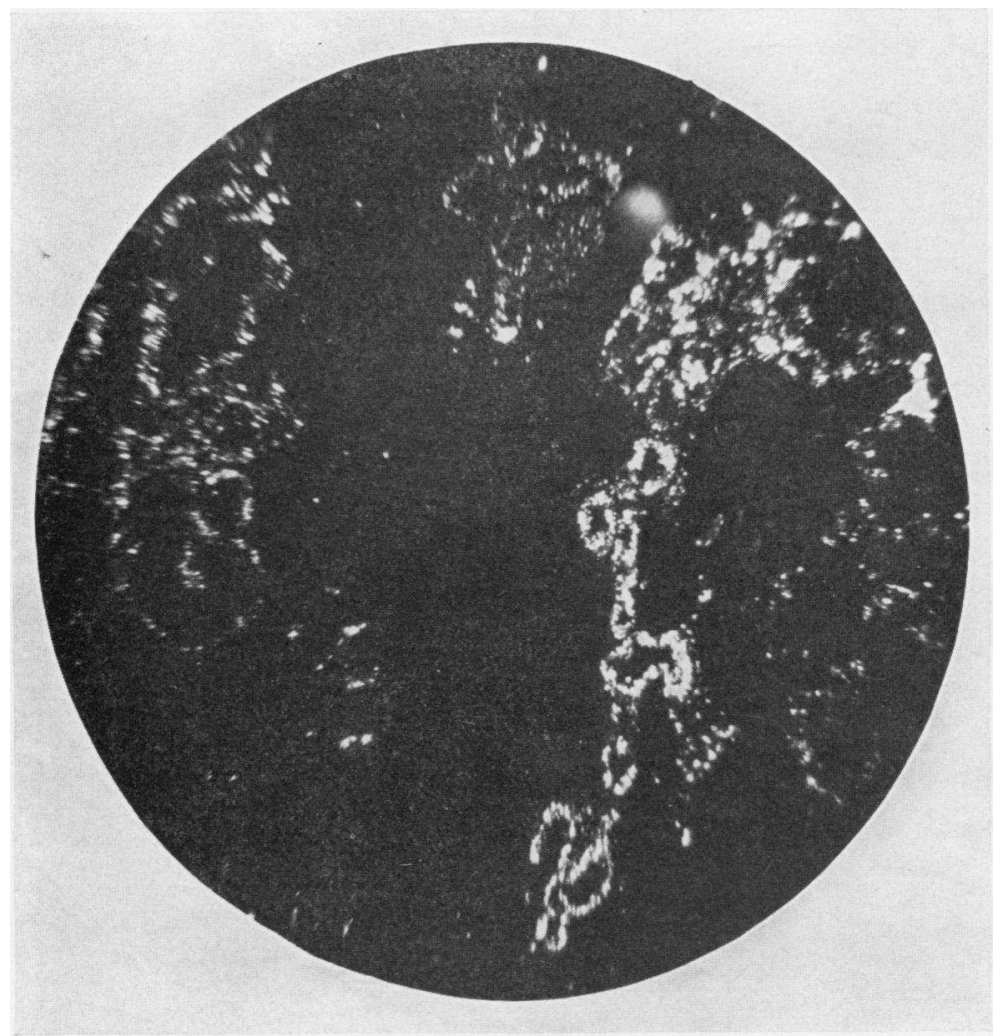

Fig. IV. Case 9. Unstained Section Observed under Crossed Nicol's; Showing the Selective Localization of the Doubly Refracting Substances (Lipom) in Certain Portions of thf. Tubules; $\times 375$ 